\title{
The meaning of "socialization of health" to Iranian policymakers and how it can be implemented
}

\author{
Mahnaz Ashoorkhani ${ }^{1}$, Fatemeh Rajabi*2, Reza Majdzadeh ${ }^{3}$ \\ Received: 11 Aug 2018 \\ Published: 15 Feb 2019
}

\begin{abstract}
Complex nature of health and disease, the impact of various socioeconomic factors on the health system arrangements and health of the society, and also the impact of health on the social and economic conditions of the society require a social approach to health. This necessity has led to the creation of new policies and programs, under the name of socialization of health, to strengthen the social approach to health in the health system of Iran. However, there must be more convergence between various stakeholders about the definition, conceptual framework, and different dimensions of this term (socialization of health). Using the experts' opinions and scientific evidence, we clarified the concepts and different dimensions of socialization of health to be used by healthcare policymakers and managers.
\end{abstract}

Keywords: Community participation, Good governance, Social determinants of health, Accountability

Conflicts of Interest: None declared

Funding: None

*This work has been published under CC BY-NC-SA 1.0 license.

Copyright $\odot$ Iran University of Medical Sciences

Cite this article as: Ashoorkhani M, Rajabi F, Majdzadeh R. The meaning of "socialization of health" to Iranian policymakers and how it can be implemented. Med J Islam Repub Iran. 2019(15 Feb);33:6. https://doi.org/10.47176/mjiri.33.6

\section{Introduction}

Similar to many other countries, Iran's health system faces many challenges, one of the most prominent of which is the rise in the burden of non-communicable diseases, aging of the population, and the subsequent rise in health costs. Under such circumstances, many factors, such as utilizing the effective forces of the society, can support the health system to achieve its goals (1-3). One of the most important goals of the Ministry of Health and Medical Education (MOHME) in recent years has been to strengthen the social perspective in the health system; and such measures as establishing the social deputy in the ministry and universities of medical sciences are among the examples.

Corresponding author: Dr Fatemeh Rajabi, frajabi@tums.ac.ir

1. Department of Health Education and Promotion, School of Public Health, Tehran University of Medical Sciences, Tehran, Iran.

2. Community Based Participatory Research Center, Iranian Institute for Reduction of High-Risk Behaviors, Tehran University of Medical Sciences, Tehran, Iran.

3. Knowledge Utilization Research Center (KURC), Community Based Participatory Research Center, and School of Public Health, Tehran University of Medical Sciences, Tehran, Iran.
Many definitions have been put forth by the authorities for the socialization of health. However, no single, accurate, and comprehensive definition has been presented for socialization of health, and there are differences in the definitions and impressions of the term. This issue can lead to confusion of the stakeholders and implementation of the relevant programs. During the period of this study, we reviewed all speeches of MOHME authorities which have been published in the media and we also attended several seminars which were held for clarifying the definition of the social health in Iran.

The English equivalent of this term is very different from the definitions mentioned by Iran's policymakers.

$\uparrow$ What is "already known" in this topic:

Great efforts are being made in Iran as "socialization of health" to improve the country's health features. However, the exact definition of this term, scope and borders of activities have not yet been well-defined.

$\rightarrow$ What this article adds:

The definition intended for "socialization of health" in Iran is not identical to its worldwide definition. In Iran, this term refers to such measures as community engagement, intersectoral collaboration, and dealing with the social determinants of health. Moreover, the success of these efforts, in addition to a clear-cut definition, relies on having a concrete plan of action and robust implementation. 
The closest English equivalent is socialized health or socialization in health. In the Oxford Dictionary, 'socialized medicine' has been defined as "the provision of medical and hospital care for all by means of public funds". It refers to items such as insurance coverage, establishment of universal health coverage, and provision of medical and hospital care with the lowest costs. In most cases, the source of provision of this budget is public and refers to such sources as taxes. Thus, it seems that the English equivalent of this term is not consistent with the concept used in Iran. Therefore, due to its complicated and multidisciplinary nature, the need for a forum consistingof different specialties seems necessary to present an accurate, comprehensive, and acceptable definition for this term.

\section{Different definitions of socialization of health}

Several subjects are involved in the intention of different bodies when they talk about the socialization of healthin Iran. These include community participation, strengthening intersectoral and intrasectoral collaboration, emphasizing social determinants of health, and accountability of medical and health education and research systems.

The most outstanding approach in this domain is encouraging community participation toward achieving health goals. In the Alma-Ata Declaration, the World Health Organization (WHO) recognized participation as a fundamental element of health policies and the significance of informed involvement of stakeholders, particularly the public, in the design and implementation of health service programs (4). Participation takes place at various levels, such as needs assessment, planning, mobilization, training, implementation, monitoring, and evaluation (5). A review of the world's literature indicates the significance of interacting with the community to use the potential of the community. Measures based on community participation have had more sustainable effects on health (2). In recent literature, community-based participation is a key element of PHC and health system reform (6). Moreover, community-based participation has been recognized as a means of reducing health system costs (2). In such a situation, citizens have the opportunity to identify priorities and actively decide on the allocation of resources for real priorities, which leads to a reduction in inequality in the use of financial resources $(1,2)$. Such measures will increase the level of participation, commitment, and trust of the people, leading to more equitable public spending; they will also result in reduction of health inequalities, increased social capital, and greater transparency and accountability of the government $(2,4$, $7,8)$. The shortage of health budget is a common problem among developing countries. In these communities, the government is not able to provide health services to everyone, and nongovernmental organizations (NGOs) and charities contribute to the healthcare fund (9). In Iran, the study of scientific literature and the opinion of experts in the field of health, emphasizes the importance of the financial support of the community in promoting health (10). Another aspect of the social approach in health is strengthening intersectoral and intrasectoral collaboration
(11). Many of the strategic challenges of the lack of success of PHC are rooted in weak strategies of establishing intersectoral collaborations (12). Policies, guidelines, and measures taken by other sectors, such as the industry, agriculture, animal husbandry, food, housing, communications, transportation, etc., all have direct effects on health; thus, creating an atmosphere of cooperation and interaction between organizations is a necessity $(11,13,14)$. Based on this very necessity, 'Health in All Policies' (HiAP) has been proposed. To achieve HiAP, the following have been proposed: (i) good governance; (ii) development of strong and sound partnerships based on codesign, co-delivery, and co-benefits; (iii) dedicated capacity and resources; and (iv) the use of evidence and evaluation (11).

Another one of these approaches is laying emphasis on social determinants of health (SDH), meaning, factors that control health and disease often fall outside the health domain. Factors such as the living environment, nutrition, education, occupation, income, social class, etc., affect health in the society, its distribution in the society, and creation of inequity $(15,16)$. Therefore, the health system needs an approach that can examine these factors and plan and intervene to control them and reduce their negative effects on the health of the community. Here, the joint role of community participation and intersectoral collaborations is both important and necessary.

\section{Socialization of health prerequisites}

Emphasizing socially accountable medical education and research is one of the prerequisites of socialization of health. Graduates of the health domain are the first level of contact with the society. Thus, it is essential for medical students to be educated with a social perspective to solve community health problems in the future. Educational content based on community needs, communitybased educational context, and strengthening of community-based thinking, as opposed to an individualistic and patient-oriented approach, are all important for promoting community health (17). A review of the global literature shows that strengthening community-based and accountable education has garnered attention among different countries in the social approach towards health. Creating a context for educating students among the society has been observed in the experience of many developed countries and those that are aware of the significance of the community. In Iran, one noticeable act in this regard was the integration of medical education into the Health Ministry and the establishment of the MOHME. This step was taken in 1984and was aimed at training students with expectant capabilities in service delivery and required numbers (18). Research studies that have been designed in line with the community's needs and whose results are likely to be applied are the requisites of every research system. In addition to meeting the community's true needs, CBPR (Community Based Participatory Research) studies lead to the empowering of the community and utilization of community's capacities and local organizations in promoting the local communities' health due to their special methodology. Many studies have indicated the positive 
impacts of these types of research (19-21).

Recent steps, such as reform and innovation in medical education, and moving towards accountable education, updating the curriculum according to the country's health needs, launching specialized disciplines based on a social approach (such as health promotion, community medicine, community-oriented nursing, oral health and its likes), and allocation of promotion scores in educational activities at community level have all been taken toward the fulfillment of this purpose. Admission in some of these programs halted recently, which must be considered as a movement against the socialization of health strategy.

For socialization of health to materialize, the role of efficient governance is significant. The characteristics of a good governance are being responsible, transparent, accountable, equitable and multifaceted, effective and efficient, participatory, cohesive, and law-abiding (10, 11, 14). It should receive particular attention in the governance section, and necessary planning should be done to achieve it. Some studies have clearly indicated the direct positive effect between governance and health. In good governance, feelings of trust, security and personal communications are enhanced. The role and significance of good governance is more prominent in contexts where financial resources are limited (22).

\section{The way forward}

To implement the process of socialization of health, it is essential to have a vision and a clear roadmap. Earlier experiences in the country also indicate the significance of this issue. Therefore, a roadmap should be designed first and then steps should be taken toward it, bearing in mind all the capabilities and available resources, one which is currently absent. The first and foremost step in planning is to reach a unified, precise, and comprehensive definition. This will form the backbone of an accurate planning for effective measures to accomplish the goal and to design indices and criteria for evaluating the rate of success in reaching the predetermined goals. Unfortunately, a single and clear definition of social health has not been presented and various authorities and sectors have different impressions of it and have based their operational steps upon them.

Evidence suggests the importance and impact of community involvement in promoting health and increasing equity in the health sector. Community participation at all levels should be considered and not just a demonstration of community involvement. Obtaining a high level of participation in the society is not achieved easily and prerequisites at community, organizational, and national level should be established. For this, empowering people to participate fully and effectively, strengthening the framework for inter organizational cooperation, and achieving good governance indicators at the national level are the requirements. Thus, we recommend having a specific and accountable stewardship for the roadmap of the socialization of health. Describing a vision of the desired future of socialized health, which is agreed upon by both policymakers and directors from different domains, is a necessity to shape the policies, programs, and measures taken by different organizations in this regard. Defining concrete measures and appointment of national tasks alongside relevant, transparent, and measurable indices help monitor this path. Also, impact assessment of interventions in this domain can promote future activities.

Some of the most important interventions at the national level areas follow: strengthening the HiAP approach; strengthening intersectoral collaboration in line with the society's health goals; preparing grounds for actualizing correct and constructive participation in the domains of education, research, health, administration and decisionmaking toward realizing the socialization of health; providing environments for constructive engagement of the public, domestic, and international NGOs; adopting policies that strengthen trust and social capital; advancement of the research system towards community health priorities and CBPR; and advancement of the educational system towards the needs of a health-oriented and accountable community.

Some of the recommendations at academic level are as follow: prioritizing the social approach in the health domain and its various dimensions; having an operational plan appropriate to the national vision and programs; strengthening intra-academic and extra-organizational collaboration; encouraging the local community and other organizations to participate; securing financial resources from charities and NGOs; and advancing communityoriented and accountable education and participatory research.

By having knowledge about different dimensions of socialization of health and the requisites and by providing the infrastructures for guiding a clear and transparent roadmap, we can take effective steps in this path through the informed and active participation of the community.

In conclusion, what policy makers mean by introducing the term socialization of health is not necessarily aligned with its common definition in the global literature. Iran's policy makers use this term to refer to a set of activities directed toward community participation that strengthen intersectoral and intrasectoral collaboration, emphasizing on social determinants of health, accountability of medical and health education, and research systems, which all fitted and urgent for the country. However, a clear definition and translation to concrete programs for sharing with stakeholders and firm implementation are necessities for the success of such good intention and direction.

\section{Conflict of Interests}

The authors declare that they have no competing interests.

\section{References}

1.Luis IP, Martínez S, Alvarez A. Community engagement, personal responsibility and self help in cuba's health system reform. MEDICC review. 2012;14:44-7.

2. George AS, Mehra V, Scott K, Sriram V. Community participation in health systems research: a systematic review assessing the state of research, the nature of interventions involved and the features of engagement with communities. PLoS One. 2015;10(10):e0141091. 
3. O'Mara-Eves A, Brunton G, Oliver S, Kavanagh J, Jamal F, Thomas J. The effectiveness of community engagement in public health interventions for disadvantaged groups: a meta-analysis. BMC Public Health. 2015;15(1):129.

4. Heritage Z, Dooris M. Community participation and empowerment in Healthy Cities. Health Promot Int. 2009;24(suppl-1):i45-i55.

5. Kickbusch I, Gleicher D. Governance for health in the 21st century: WHO Regional Office for Europe Copenhagen; 2012.

6. Lewin S, Lavis JN, Oxman AD, Bastías G, Chopra M, Ciapponi A, Flottorp S, Martí SG, Pantoja T, Rada G. Supporting the delivery of cost-effective interventions in primary health-care systems in lowincome and middle-income countries: an overview of systematic reviews. Lancet. 2008:372(9642):928-39.

7. Almedom AM. Social capital and mental health: An interdisciplinary review of primary evidence. Soc Sci Med. 2005;61(5):943-64.

8. Organization WH. WHO global strategy on people-centred and integrated health services: interim report. 2015.

9. Rifkin SB. Examining the links between community participation and health outcomes: a review of the literature. HPP. 2014;29(suppl_2):ii98-ii106.

10.Sciences Ao. Meeting of Experts on Socializing Health. 2017.

11.Lin DV. Progressing the Sustainable Development Goals through Health in All Policies: Case studies from around the world.: World Health Organization; 2017.

12.Adeleye OA, Ofili AN. Strengthening intersectoral collaboration for primary health care in developing countries: can the health sector play broader roles? J Environ Public Health. 2010.

13.Rigby E. Economic Policy: An Important (but Overlooked) Piece of " Health in All Policies": Institute of Medicine of the National Academies; 2013.

14. Organization WH. Governance for health in the 21st century. 2012

15. Marmot M, Friel S, Bell R, Houweling TA, Taylor S, Health CoSDo. Closing the gap in a generation: health equity through action on the social determinants of health. The Lancet. 2008;372(9650):1661-9.

16.Embrett MG, Randall G. Social determinants of health and health equity policy research: exploring the use, misuse, and nonuse of policy analysis theory. Soc Sci Med. 2014;108:147-55.

17.Rajabi F, Majdzadeh R, Ziaee SAM. Trends in medical education, an example from a developing country. Arch Iran Med. 2011;14(2).

18.Nedjat S, Yazdizadeh B, Ashorkhani M, Maleki K, Majdzadeh R. Effect of Ministry of Health and Medical Education structure on application of medical research. Hakim Res J. 2008;11(3):1-10.

19.Salimi Y, Shahandeh K, Malekafzali H, Loori N, Kheiltash A, Jamshidi E, Frouzan AS, Majdzadeh R. Is community-based participatory research (CBPR) useful? A systematic review on papers in a decade. Int J Prev Med. 2012;3(6):386.

20.Wallerstein N, Duran B. Community-based participatory research contributions to intervention research: the intersection of science and practice to improve health equity. Am J Public Health 2010;100(S1):S40-S6.

21.Strasser R. Community engagement: a key to successful rural clinical education. Rural Remote Health. 2010;10(1543):1-8.

22.Ciccone DK, Vian T, Maurer L, Bradley EH. Linking governance mechanisms to health outcomes: A review of the literature in low-and middle-income countries. Soc Sci Med. 2014;117:86-95. 